REVISTA IBEROAMERICANA. Vol. LXII, Núm. 174, Enero-Marzo 1996; 185-197

\title{
LA HISTORIA OFICIAL FRENTE AL DISCURSO DE LA "FICCIÓN" FEMENINA EN ARRÁNCAME LA VIDA DE ÁNGELES MASTRETTA
}

\author{
POR \\ MONIQUE LeMAÎTRE \\ Northern Illinois University
}

Catalina Ascencio, la protagonista y narradora de la primera novela de Ángeles Mastretta Arráncame la vida ${ }^{1}$ nace, de acuerdo con la referencia que nos da en la página 33, en 1915, o sea el año en que Carranza regresa a la ciudad de México como presidente constitucional, puesto que ocupará hasta 1920. La novela empieza, sin embargo, el año del matrimonio de Catalina con Andrés Ascencio, cuando ella cuenta con quince años de edad, es decir en 1930. Desde la primera línea de la novela la narradora contrasta la realidad histórica del país con la de su patria chica, Puebla, y con la suya propia, centrando la narración sin ambages en esta última, que va a ser el eje del desarrollo de la trama, pero dejando esbozados los otros dos niveles cuyos planos vendrán, a lo largo de la narración, a intersectarse con el plano central de la vida objetiva y de la subjetividad de Catalina Ascensio. El discurso central es pues, al comienzo de la narración, el de una mujer adulta que recuerda y trata de mimetizar el hablay las vivencias de la núbil adolescente provinciana que fue, todavía enfrascada en juegos infantiles. Al relatar su breve "noviazgo" con Andrés Ascencio nos dice la narradora: "Cuando se iba yo lo acompañaba a la puerta y me dejaba besar un segundo, como si alguien nos espiara. Luego salía corriendo tras mis hermanos" (10). Es además obvia la dependencia emocional de Catalina hacia el padre al principio de la novela y los fuertes lazos que los unen a lo largo de la narración hasta la muerte de éste. En su presencia, Catalina se describe a sí misma desde un principio como niña:

Me gustaba besar a mi papá y sentir que tenía ocho años, un agujero en el calcetín, zapatos rojos y un moño en cada trenza los domingos. Me gustaba pensar que era domingo y que aún era posible subirse en un burro que ese día no cargaba leche, caminar hasta el campo sembrado de alfalfa para seguir bien escondida y desde ahí gritar: A que no me encuentras papá. Oír los pasos cerca y su voz: ¿Dónde estará esta niña? ¿Dónde estará esta niña?, hasta fingir que se tropezaba conmigo, aquí está la niña, y tirarse cerca de mí, abrazarme las piernas y reírse (...)" (10).

La transición entre su relación de hija eternamente niña frente al padre y la de esposa, hija/niña de Andrés Ascencio es nodal para comprender el desarrollo subsecuente de la personalidad de la narradora-protagonista. El símbolo-puente entre la figura del padre y la

\footnotetext{
1 Angeles Mastretta. Arráncame la vida (México: Cal y Arena, 1990). En lo sucesivo, cuando hagamos citas de esta novela, sólo indicaremos el número de página.
} 
de Andrés Ascencio es el de un sapo. El padre pretende ser un sapo cuando atrapa a la niña para darle un beso: "Ya no se puede ir la niña, la tiene atrapada un sapo que quiere que le dé un beso". El párrafo siguiente comienza: "Y de veras me atrapó un sapo. Tenía quince años y muchas ganas de que me pasaran cosas"(11). La referencia al cuento de hadas infantil que relata cómo un joven y apuesto príncipe fue convertido en sapo por una hechicera y de cómo el hechizo desaparece cuando una bella princesa lo besa sin temor a su aspecto exterior, es obvia. A lo largo de la novela padre e hija pretenderán ser novios en eternidad y la figura de la madre no le hará nunca sombra a la del padre. La ironía es que el personaje de Andrés Ascencio torna verdaderamente a ser un sapo en el sentido popular de la palabra. Llega a personificar los atributos populares del sapo como batracio repulsivo que contamina o envenena todo lo que toca (irónicamente, al final de la novela el sapo morirá envenenado por la princesa ya convertida en reina vengadora). Y es precisamente porque Andrés no se convierte nunca en príncipe azul, en verdadero alter-ego del padre que le permita a Catalina sublimar el tabú del incesto, que ésta lo seguirá buscando en la figura de otros, primero en la figura del chipileño Pablo, durante su primer embarazo y para paliar el abandono en que la tiene Andrés, después en la figura sensible y culta de Fernando Arizmendi y, por fin, en la de Carlos que simbolizan por su aspecto, sensibilidad e integridad al hombre ideal de Catalina que es el polo opuesto del cacique machista, corrupto y sanguinario con quien se casa. En la última parte de la novela, Catalina, después de su largo duelo por el asesinato de Carlos se vuelve la amante de Alonso, un personaje mucho menos idealizado que el de Carlos, su verdadero príncipe azul, a quien Andrés mandará asesinar, conciente de que no puede competir con él.

También desde las primeras páginas de la novela la narradora establece un paralelismo entre la realidad externa del país en que "pasaron muchas cosas" en 1930 y su realidad interna: "Tenía quince años y muchas ganas de que me pasaran cosas" (11). Igualmente subraya el paralelismo que existe entre su extracción social y la del general, utilizando como nexo de comunicación entre ambos la manera despectiva como éste trata a los poblanos de "pendejos" en la primera página de la novela y su reacción como narradora (mediatizada por la memoria):

Claro que estaba yo de acuerdo. Para mí los poblanos eran esos que caminaban y vivían como si tuvieran la ciudad escriturada a su nombre desde hacía siglos. No nosotras, las hijas de un campesino que dejó de ordeñar vacas porque aprendió a hacer quesos; no él, Andrés Ascencio, convertido en general gracias a todas las casualidades y todas las astucias menos la de haber heredado un apellido con escudo (9).

El discurso de ambos, Catalina y Andrés no es pues, desde un principio y a pesar de la heterogeneidad genérica y generacional, un discurso de víctima y victimario, como tampoco es un discurso revolucionario, es el discurso de la tradición hegemónica matizado por el de una clase social emergente que no olvida su extracción popular pero terminará emulando los gustos y deseos de la burguesía porfiriana venida a menos.

¿Qué pasaba en México en 1930? Bastaría con recordar que fue la época de la "Gran Depresión" que empieza con el "crack" de Wall Street y que la parálisis económica afectó profundamente al país, sobre todo a las mujeres. ${ }^{2}$ El presidente era Pascual Ortiz Rubio 
quien duraría únicamente dos años en el poder a causa de una disidencia con Calles quien seguía ejerciendo el poder detrás de la presidencia y quien contaba con el apoyo del ejército y era el jefe indiscutible del Partido Nacional Republicano organizado por él mismo después de la muerte de Obregón. En Puebla y sus alrededores, el anticlericalismo callista, que la burguesía, los antiguos hacendados y gran parte del pueblo veían como una afrenta más a su clase, los primeros, y a sus tradiciones el segundo, es brevemente mencionado por la protagonista, quien nos dice haber continuado sus estudios un poco más allá de la primaria, gracias a una beca que le fuera otorgada por unas monjas salesianas que enseñaban en un colegio clandestino:

Estaba prohibido que enseñaran, así que ni título ni nada tuve, pero la pasé bien. Todo se agradecía. Aprendí los nombres de las tribus de Israel, los nombres de los jefes y descendientes de cada tribu y los nombres de todas las ciudades y todos los hombres y mujeres que cruzaban por la Historia Sagrada. Aprendí que Benito Juárez era masón y había vuelto del otro mundo a jalarle la sotana a un cura para que ya no se molestara en decir misas por él, que estaba en el infierno desde hacía un rato. Total, terminé la escuela con una mediana cal igrafía, algunos conocimientos de gramática, poquísimos de aritmética, ninguno de historia y varios manteles de punto de cruz (12-13).

En el segundo capítulo de la novela, la narradora también menciona indirectamente la guerra de los cristeros y el conflicto entre la iglesia y el estado al describirnos el arresto del sacerdote que está oficiando el rosario en la iglesia de Santiago a donde Catalina ha ido para pedirle a la virgen el regreso de Andrés, preso como presunto homicida:

Todos cantábamos: los corazones laten por vos, una y mil veces adiós, Cuando de atrás empezaron a llegar gritos: - ¡Viva Cristo Rey! ¡Viva Cristo Rey!

Unos gendarmes entraron por el pasillo y a empujones se abrieron paso hasta el altar. Mareada por la gente y el incienso pude oír cuando uno de ellos le dijo al cura:

- Tiene usted que venir con nosotros. Ya sabe la razón, no haga escándalo. (24).

Dos páginas más adelante la narradora recuerda que al día siguiente el periódico daba la noticia de la puesta en libertad de Andrés Ascencio y el encarcelamiento del cura de Santiago, quien había recibido una sentencia de dos años de cárcel por "organizar una manifestación contra la ley de cultos". Andrés culpa al gobernador de Puebla por su arresto. En la realidad, el gobernador de Puebla era don Froylán C. Manjarrez quien fue un gran luchador social y uno de los impulsores del artículo 123 tantas veces vejado por Andrés Ascencio a lo largo de la novela. Si bien la Guerra de los Cristeros había terminado en 1929 y le había costado al país entre 70,000 y 85,000 muertos en tres años: ${ }^{3}$

2 Anna Macías. Against All Odds. The Feminist Movement in Mexico to 1940 (Westport, CT y Londres: Greenwood Press, 1982), especialmente el capitulo "The Feminist Movement in the 1930s", 125-151.

3 Jean Meyer. La Cristiada 3- los cristeros (México: Siglo Veintiuno Editores, 1974) 260 y sigs. 
(...) el grupo de presión anticlerical tuvo su apogeo de 1930 a 1934. Amaro y el general Rodríguez atacaron violentamente a la Iglesia en sus periódicos e impulsaron al gobierno a romper la tregua. ${ }^{4}$

En el primer capítulo de la novela aparece también mencionado Calles bajo el apellido de Jiménez:

Había participado en la guerra anticristera de Jiménez, le debía lealtad al jefe máximo, ni de chiste se iba a casar por la iglesia. Por lo civil sí, la ley civil había que respetarla, aunque lo mejor, decía, hubiera sido un rito de casamiento militar (14).

A Calles lo llamaban "el jefe máximo de la revolución", término que fue empleado por primera vez por Luis L. León, director del periódico callista El Nacional (Meyer-1, 353). En cuanto al personaje de Andrés Ascencio, su parecido con Maximino Avila Camacho, quien como Andrés, luchó en contra de los cristeros y llegó a ser gobernador de Puebla parece evidente. Los generales federales que pelearon en esa contienda eran tristemente célebres por su crueldad:

Los generales J. B. Vargas, A. López, Izaguirre, Maximino Avila Camacho, Daniel Sánchez, Juan Domínguez, Claudio Fox y muchos otros no hicieron sino seguir el ejemplo dado por el implacable secretario de guerra, Joaquín Amaro, de quien Lawrence hizo justamente su Huitzilopochtli, reencarnación de la divinidad sangrienta, que tiñe su manto en la sangre del prisionero indefenso (Meyer-1, 251).

Conforme la novela se va desarrollando nos vamos enterando de la crueldad y arbitrariedad de Andrés Ascencio (cuyo apellido es también simbólico). La misma Catalina nos dice, al final del tercer capítulo, que ya para el año de 1931 su esposo era jefe militar del estado de Puebla y añade, en retrospectiva: "Creo que desde entonces se convirtió en un peligro público y que desde entonces conoció a Heiss y a sus demás asociados y protegidos" (28). El personaje de Heiss está probablemente inspirado en el del millonario norteamericano-poblano Willaim Oscar Jenkins Bidd, nacido en 1863 en Shelbyville, Tennessee y muerto en Puebla en 1963. El 19 de octubre de 1919, y siendo Jenkins cónsul norteamericano en Puebla fue secuestrado. El gobierno de Carranza lo vió como un autosecuestro inventado por Washington para justificar mayores presiones sobre Carranza mientras que los Estados Unidos lo utilizaron como ejemplo del clima de inseguridad en México bajo el gobierno del mismo Carranza, clima poco propicio para las inversiones de capitales estadounidenses. ${ }^{5}$ En la historia real, William Jenkis estuvo afiliado a los Avila Camacho, especialmente a Maximino y se dedicó a fabricar alcohol ilegalmente en los años veinte en su ingenio de Atenanzingo.

\footnotetext{
${ }^{4}$ Jean Meyer. Op. cit., 354-355.

${ }^{5}$ Rafael Ruiz Harrell. El secuestro de William Jenkins (México y España: Planeta, 1992). Ver la reseña que Gerardo Ochoa Sandy hace de este libro en Proceso, No. 833 (19 de octubre de 1992) 5859.
} 
Por otra parte, continúa la lucha por la reivindicación de los derechos ganados por la Revolución para el campesinado y la incipiente clase obrera, derechos aún no patentizados (muchas de las reformas sociales logradas por la Revolución no se verán implementadas hasta el advenimiento a la presidencia del general Lázaro Cárdenas en 1934 y más específicamente después de su ruptura con Calles en 1935). Es a ésta época a la que se refiere la narradora a través de sus recuerdos de la adolescente protagonista, así como a la lucha por el poder llevada a cabo por los nuevos caciques surgidos de la misma Revolución:

Fue también la época en la que el desdén del pueblo hacia los dirigentes alcanzó su más alto grado, ya que en medio de la miseria general los escándalos del enriquecimiento y de la corrupción son más insoportables. La demagogia verbal no engaña a nadie, los "caudillos" militares se convertían en hacendados, y esos Cresos advenedizos se disimulaban mal tras de la máscara de Espartaco. Con Calles era el ejército el que dominaba (...) (Meyer1, 354).

Los datos históricos van a ir engarzándose al plano subjetivo de la historia de Catalina, reflejando su paulatina concientización (y la dialéctica de su liberación) y también su educación política que corre paralela a su educación sentimental tejiendo así el complejo discurso de lo que fue, para una mujer singular, la vida en el México de los años 30 y 40.

Mientras la joven Revolución está experimentando un verdadero rito de pasaje que la llevará de la teoría a la praxis, Catalina pasa, en el primer capítulo de la novela, por el rito de pasaje más importante para una mujer en el mundo patriarcal, el de la pérdida de la virginidad y el de la ceremonia del matrimonio. A pesar de los fuertes lazos que, según la narradora, existían entre ella y su padre, éste, al igual que el resto de la familia, no hizo caso de los rumores que corrían sobre las muchas mujeres de Andrés Ascencio ni parece haberse preocupado mayormente de que éste se llevara a Catalina "a conocer el mar". Al decir de la misma narradora adulta que recuerda sus reacciones de adolescente pero las califica desde una perspectiva adulta, las razones de sobrevivencia económica parecen haber sido las que rigieron el comportamiento de sus padres y su aceptación de Andrés Ascencio como futuro yerno:

Cuando acabó la semana me devolvió a mi casa con la misma frescura con que me había sacado y desapareció como un mes. Mis padres me recibieron de regreso sin preguntas ni comentarios. No estaban muy seguros de su futuro y tenían seis hijos, así que se dedicaron a festejar que el mar fuera tan hermoso y el general tan amable que se molestó en llevarme a verlo (12).

El tono utilizado por la narradora es engañosamente irónico pues al comparar la reacción de su padre el día en que Andrés Ascencio le anuncia su decisión de casarse con Catalina:

Le había dicho que se quería casar conmigo, que si no le parecía tenía modo de convencerlo, por las buenas o por las malas. - Por las buenas, general, será un honorhabía dicho mi padre incapaz de oponerse (16-17). 
La narradora contrasta esta escena con lo que recuerda que Andrés le dijera, años más tarde, en relación con el futuro matrimonio de su hija Lilia y nos percatamos que la situación de la mujer no ha cambiado en lo esencial ya que ésta seguía siendo, a fines de los cuarenta, una mercancía de trueque en el vasto mercado del poder patriarcal. La única diferencia estriba en que el padre de Catalina es pobre y Andrés Ascencio es rico, en que el primero nos es presentado como débil e impotente ante el evento y el segundo como prepotente:

- ¿Piensas que yo voy a ser con mis hijas como tu papá contigo? Ni madres. A mis hijas no se las lleva cualquier cabrón de la noche a la mañana. A mis hijas me las vienen a pedir con tiempo para que yo investigue al cretino que se las quiere coger. Yo no regalo a mis crías. El que las quiera que me ruegue y se ponga con lo que tenga. Si hay negocio lo hacemos; si no, se me va luego luego a la chingada. Y se me casan por la iglesia, que ya se jodió Jiménez en su pleito con los curas (17).

Políticamente el círculo se ha cerrado y los nuevos caciques han reemplazado a los viejos. La polarización entre políticos masones y potentados de la iglesia se ha convertido en una nueva alianza tácita en contra del pueblo y se utilizan los ritos de la tradición únicamente como símbolos de estatus social y de poder, vaciándolos del contenido orgánico que tienen para el pueblo. En la novela, las mujeres, al igual que el pueblo, no tienen ni voz ni voto en el asunto; en el caso de Catalina, ésta más bien añorará siempre el no haber tenido un matrimonio tradicional:

Eso no me hubiera cambiado la vida, pero podría jugar con el recuerdo como juegan otras. Podría evocarme caminando el pasillo de regreso apoyada en Andrés y saludando desde la altura de mi nobleza recién adquirida, desde la alcurnia que todos otorgan a una novia cuando vuelve del altar (14).

Una y otra vez la narradora recalcará, a lo largo de la novela, la importancia de los ritos para las mujeres, sea por medio de sus comentarios subjetivos y retrospectivos sobre sus vivencias personales, sea por medio de descripciones como la del rosario en la iglesia de Santiago en el segundo capítulo o las de las clases de cocina en el mismo. A través del rito la mujer parece recobrar, aunque sea por breves instantes, su centralidad en el esquema orgánico del universo, centralidad que le es constantemente negada por un sistema patriarcal que la margina a cada paso y en donde se le trata como a una niña pequeña o se le utiliza para descargar en ella todas las responsabilidades que entorpecerían (en el caso de esta novela) el ascenso de Andrés Ascencio al poder y la consumación de sus caprichos y deseos.

La madre está totalmente ausente de la educación sentimental y sexual de la narradoraprotagonista, quien recurre a la gitana del barrio de la luz con "fama de experta en amores" (13) para que le enseñe a "sentir" cuando hace el amor con Andrés y con quien lleva a sus amigas Mónica y Pepa para que convenza a la primera que los niños no se conciben con un beso de lengua, pues la gitana tiene una autoridad que ella, Catalina, a pesar de estar casada, no tiene sobre sus amigas. En el mundo marginado y subterráneo de las mujeres, aquellas que no cuentan sino con su cuerpo y que lo aceptan sin pudibundería y remilgos adquieren poderes de hechiceras-sacerdotizas sobre las adolescentes en vías de descubrir su propia sexualidad. Catalina, inmersa dentro de una institución patriarcal solamente puede soñar 
con transgredirla, lo que hará, y pagará eventualmente el precio de esa transgresión, pero no conocerá nunca la libertad de la gitana que no llevaba "calzones ni fondo ni sostenes" y le enseña gráficamente en dónde se encuentra el "timbre" y qué es lo que hay que hacer para "sentir". En contraste, la madre de la protagonista nos es descrita como una mujer con constantes e insubstanciados "presentimientos" (15) y quien, cómicamente, reacciona ante la descripción que Teresa, hermana de Catalina, le hace de los ruidos que Catalina hiciera la noche anterior al masturbarse por vez primera, queriendo llevarla al doctor pues "Así le había empezado la tuberculosis a la dama de las camelias" (14). O sea que la madre de Catalina niega consciente o inconscientemente su cuerpo y el de todas las mujeres, hasta el punto de que nunca "hablaba de eso" (de la menstruación) y la "enseñó" a lavar "los trapos rojos" cuando nadie la pudiera ver (27).

En contraste con la madre, la joven recién casada de los primeros capítulos de la novela se nos describe, retrospectivamente, como una adolescente sana, llena de curiosidad por la vida, gozosa y hasta enamorada de un marido a quien apenas conoce pero que le ha hecho descubrir el placer sexual y el del lecho compartido, además del de las salidas mañaneras a caballo. Una adolescente que va a ir enfrentándose a cada uno de los cambios que le impone, desde fuera, el otro, su marido, con una adaptabilidad que nunca es, sin embargo, entrega incondicional al papel de mujer sufrida que su socio le exigiría.

La adolescente de diezy seis años que en un mismo día presencia el arresto de su esposo por unos soldados que tienen una orden de aprehensión contra él por homicidio, y el arresto del cura de la iglesia a donde va a pedirle socorro a la virgen para que ayude a Andrés, por otros soldados, no corre a refugiarse a casa de sus padres sino que regresa a la suyay, además, se entera de cuáles son las acusaciones en contra de su marido por voz de Chema. Además, al día siguiente se enfrenta a la opinión de sus amigas, al famoso "qué dirán" al asistir como le correspondía a su clase de cocina en casa de las Muñoz. A su manera, sobrevive también el tedio de su vida provinciana a la cual el marido se asoma de vez en cuando, hasta el punto de soñar con la visita de "Pepe Flores" (su menstruación) y de esperar su partida emborrachándose con anís.

Lo mismo sucede con su "instinto maternal". Instinto cuyas bases biológicas (o instintivas) no han podido probarse aún. ${ }^{6}$ Catalina nos resume así (en retrospectiva) lo que experimentó al estar embarazada por primera vez:

Tenía yo diecisiete años cuando nació Verania. La había cargado nueve meses como una pesadilla. Le había visto crecer a mi cuerpo una joroba por delante y no lograba ser una madre enternecida. La primera desgracia fue dejar los caballos y los vestidos entallados, la segunda soportar unas agruras que me llegaban hasta la nariz. Odiaba quejarme, pero odiaba la sensación de estar continuamente poseída por algo extraño. Cuando empezó a moverse como un pescado nadando en el fondo de mi vientre creí que se saldría de repente y tras ella toda la sangre hasta matarme (31).

6 Para un extensivo estudio del tema ver Nancy Chodorow. The Reproduction of Mothering Psychoanalysis and the Reproduction of Gender (Berkeley, Los Angeles, Londres: University of California Press, 1978). En especial "Why Women Mother", Cap. 2, 11-39. 
Con un dejo de humor la narradora añade que "eso fue lo único bueno que tuvo mi embarazo de Verania" (32) al referirse a su relación sexual con su amigo de infancia, Pablo el lechero. Esta actitud de Catalina que va en contra del canon patriarcal que define el embarazo y la maternidad como el estado ideal de la mujer se repetirá más adelante, en el capítulo diez, cuando Catalina visita a la Bibi durante su segundo embarazo:

-Son horribles las panzas, ¿no?

- Horribles. Yo no sé quién inventó que las mujeres somos felices y bellas embarazadas. - Seguro fueron los hombres. Ahora, hay cada mujer que hasta pone cara de satisfacción. - ¿Qué les queda?

-Pues siquiera el enojo. Yo mis dos embarazos los pasé furiosa. Qué milagro de la vida ni qué la fregada. Hubieras visto cómo lloré y odié mi panza de seis meses de Verania cuando se llenó de nísperos el árbol del jardín y no pude subirme a bajarlos. Todos los años era la campeona, les ganaba a mis hermanos como por tres canastas, y de repente voy entrando a casa de mis papás y veo a mis hermanos trepados en el árbol concursando sin rival (95-96).

Además, cuando su hija Verania cuenta apenas un mes de vida, Andrés le trae a dos otros hijos suyos de la edad de Catalina, Octavio y Virginia. Su incipiente maternidad se ve pues mediatizada casi de inmediato por el fantasma de la madre de estos dos jóvenes, Eulalia, quien por un tiempo parece imponérsele desde la ultratumba como modelo a seguir a través del relato que Andrés hace de su relación con ella, y sobre todo porque la narradora nos dice que Andrés "hablaba de ella como de un igual. Nunca lo oí hablar así de otra mujer" (35). La narradora-protagonista recuerda inclusive que "Veneré la memoria de Eulalia, quise hacerme de una risa como la suya, y cien tardes le envidié con todas mis ganas al amante simplón y apegado que mi general fue con ella" (43). El largo relato de la vida de Andrés con la "ex-soldadera maderista" Eulalia y con su padre, Don Refugio, nos es narrado por la protagonista como se lo narrara Andrés en aquél entonces y las reacciones de Catalina al relato que Andrés le hiciera son también las de la joven de 17 años que fue. La narradora adulta no califica este relato sino hasta el principio del capítulo siguiente en donde nos indica cómo se enteró, años después de que no había sido sino una mentira. Pero aún así se trata de una mentira parcial, o sea de una ficción parcial engarzada en la ficción de la novela para introducir en el plano histórico de la misma eventos de la Revolución mexicana que la protagonista no puede narrarnos directamente pues o no había nacido o era una criatura cuando estos tuvieron lugar. Además, al establecer en el capítulo siguiente que Andrés había sido no un seguidor de Madero, sino un militar bajo las órdenes del traidor Huerta, reivindica el lado idealista y utópico de la Revolución traicionado a dos niveles, el de la historia objetiva y el del personaje de ficción, Andrés Ascencio. Así, gran parte del capítulo cuarto narra los acontecimientos históricos que tuvieron lugar en México entre 1914 y 1915. La toma de Chilpancingo por Zapata, y la de Torreón por Villa, el desembarco de los infantes de marina estadounidenses en Veracruz, la llegada de Obregón a la Ciudad de México así como la de Carranza, la Convención de Aguascalientes, la entrada de Villa y Zapata a la capital, la guerra de facciones, la entrada de Obregón al D.F. y su expulsión de los curas españoles que no pagaran la contribución que se les acababa de imponer, la huida de Obregón y la hambruna que asoló a la ciudad de México bajo la Convención. También en 
este capítulo la narradora introduce al personaje de Rodolfo o "Fito", amigo de infancia de Andrés pues ambos son de Zacatlán, Puebla y quien se convierte en padrino del hijo de Andrés y Eulalia, Octavio. Fito trabaja para Carranza, cuyo gobierno acababa de ser reconocido por los Estados Unidos y Andrés pasará de ser huertista a ser carrancista en su ascenso al poder. Fito llegará a ser presidente de la república en la narración ficticia y su presidencia corresponderá con la presidencia de Manuel Avila Camacho en la realidad histórica, o sea que de ser Andrés una parodia de Maximino Avila Camacho, Fito es una parodia de su hermano Manuel (convertido en compadre en la novela). En cuanto a la ficción dentro de la ficción del capítulo cuarto, el narrador, Andrés, quien habla por intermediario de la narradora, Catalina, éste elimina oportunamente a Eulalia una vez que la "ficción maderista" deja de serle útil y la hace sucumbir como víctima de la epidemia de tifo que asoló a la capital ese año.

En el quinto capítulo saltamos a 1934, el General Aguirre(Cárdenas en la historia real) es candidato a la presidencia de la república y Andrés (Maximino Avila Camacho en la realidad) es candidato a la gubernatura del estado de Puebla. El segundo embarazo de la protagonista no ha resultado más agradable que el primero: "Después de Verania nació Sergio. Cuando empezó a llorar y sentí que me deshacía de la piedra que cargaba en la barriga, juré que ésa sería la última vez" (43). A pesar de ello la narradora nos dice haberse vuelto, durante ese período "una madre obsesiva" quizá por el abandono en que Andrés la tenía, ocupado como estaba en campañas políticas y negocios sucios con el norteamericano Heiss. La hija de Eulalia y Andrés, Virginia, desaparece un día en que no regresa de una compra y el padre no parece alterarse en lo más mínimo. La da por muerta y en cambio le trae a la narradora otras cuatro hijas de dos mujeres distintas, una de ellas una novicia que Andrés había seducido en Tlalpan durante la persecusión religiosa. Las mujeres y las hijas de Andrés Ascencio van así marcando las etapas de la Revolución y de la ascención al poder de Andrés. Al cuidado de todos estos niños o adolescentes van a ir quedando extrañas que van a a reemplazar a Catalina en su papel de madre, mientras ella asume cada vez más el de consorte del hombre en el poder, Andrés. Las primeras serán "unas nanas de la sierra más infantiles que ellos" (44). El papel de gobernadora le va a permitir a la narradoraprotagonista irse enterando de cómo funciona la política nacional e ir cuestionando el discurso hegemónico al contrastarlo con sus propias vivencias como esposa del gobernador, quién, paulatinamente, se convertirá en su antagonista, mientras que otras mujeres le servirán de ayudantes en el sentido greimasiano y objetivo (las nanas y sirvientas, su propia hermana Bárbara quien se vuelve su secretaria). Un ejemplo de ello es la mención que hace la narradora del voto que se le otorgara a las mujeres en algunos estados bajo Cárdenas y que en Puebla, a decir de ella "sólo celebraron Carmen Cerdán y otras cuatro maestras", pero que Andrés utiliza demagógicamente en sus discursos:

Un día, en Cholula, empezó uno diciendo que varias mujeres se le habían acercado para preguntarle cuál podía ser su apoyo a la Revolución y que él les había respondido que ya el General Aguirre con su sabiduría popular había dicho una vez que las mujeres mexicanas debían unirse para defender los derechos de las obreras y las campesinas, la igualdad dentro de las relaciones conyugales, etcétera. De ahí para adelante no le creí un sólo discurso (45). 
La protagonista no accede nunca al poder, nos va hilvanando su dialéctica sin explicaciones innecesarias, simplemente a través de la narración de los hechos, de la desaparición de todos aquellos que osan, aún mínimamente, resistirse a él, pero su cohabitación con el poder únicamente logra aislarla cada vez más, esclavizarla cada vez más. Dentro de los parámetros de sus deberes de gobernadora hace lo que puede, liberar a una loca que no está loca, darle empleo a una sirvienta que ha sido despedida por estar encinta y haber tratado de auto-abortarse ante la inminencia del desempleo. En el primer caso es interesante notar el ninguneo total de la mujer sin recursos o apoyo; ambas "locas" salen del manicomio con Catalina sin que nadie se dé cuenta de su ausencia (50). Catalina se las arregla para que ambas resuelvan sus problemas. En el segundo caso, Lucina se convertirá en la "nana" de toda la familia, pero no sin antes perder a su propia criatura (65). Lucina, sin embargo, ha sido también utilizada por Catalina como medio para vengarse de Marilú, quien a su vez ha sido un objeto de trueque entre su padre empobrecido y el nuevo rico Julián Amed, cuya fortuna proviene también de un crimen (59). Es decir que la narradora nos ofrece un verdadero caleidoscopio de la dialéctica del poder en donde las mujeres muchas veces ayudan a perpetuar el mismo sistema del cual son víctimas. Catalina tiene cada vez más conciencia de ello conforme avanza su narración. Llega a envidiar a las amantes de Andrés pues ellas no tienen que ser cómplices de sus crímenes, mientras que ella es su cómplice oficial a pesar suyo (54-55). Trata también de ayudar a su padre, sacrificándole su caballo favorito, Mapache, para que Andrés se lo regale a un hombre a quien Catalina desprecia, Heiss, a cambio de que deje al padre fuera de sus "negocios". O sea que Catalina trata de salvar del naufragio a quien puede, hasta el momento en que se percata de que tiene primero que salvarse a sí misma pues la corrupción y la inmoralidad del status quo, simbolizado por Andrés, amenazan perpetuarse en su propio hijo. De allí que decida, al final del capítulo sexto "cerrar el capítulo del amor maternal" (66). Esta declaración marca un cambio importante en el discurso de Catalina Ascencio. No significa en realidad que deje de querer a sus hijos o preocuparse por ellos pues muchos detalles en el resto de la novela desmienten esa actitud. Al principio del capítulo séptimo, poco después de tomar la decisión de "cerrar el capítulo del amor maternal", por ejemplo, sueña a sus hijos "con sangre en la cara"Y le comenta a Luci cuando ésta le trae el desayuno: “-Pobres niños, ¿verdad Luci?” (69). Quiere más bien decir que, a partir del momento en que se da cuenta de que únicamente está perpetuando la repetición del sistema patriarcal autocrático y caciquista que ve ya reflejado en el pequeño Sergio, decide adoptar una actitud de resistencia frente al status quo. De ayudante pasiva (tácita cómplice) de Andrés pasará a ser su antagonista. Irónicamente, utilizará precisamente su acceso a la crónica oral, a la historia testimonial de otras mujeres, aquella que el sistema patriarcal ningunea como "chismes" para ir reconstruyendo la verdadera historia de aquella época en Puebla y en México, los crímenes, los abusos de poder, la demagogia. La misma narradora-protagonista repetirá a lo largo de la narración que "en Puebla todo pasaba en los portales". Y es ese estribillo el que llegará a simbolizar la historia no-oficial del discurso de la novela. El conocimiento de la verdad de los hechos le otorga cierto tipo de poder sobre Andrés, poder relativo que la empuja a arriesgarse a chantajearlo, por ejemplo, y recobrar así su caballo Mapache (67-69). La dialéctica de la liberación de Catalina es lenta, sin embargo, y está además teñida por su propia inserción en la lucha de clases. Al seducir Andrés a la sobrina de un ex-novio de Catalina, José Ibarra, 
quien había cedido ante las presiones de su familia de dejar de verla pues ella era demasiado pobre para él, Catalina saborea el placer de la venganza: "A mí no me dió coraje, qué coraje me iba a dar, si toda la familia sigue cargando con la vergüenza" (71). El rechazo de Andrés por parte de Catalina sigue sin embargo su curso y está relacionado no con las infidelidades de aquél que Catalina ya ha dado por sentadas sino con sus crímenes. Es después del asesinato del licenciado Maynez cuyo cuerpo despedazado es depositado por "alguien" en la puerta de su casa, cuando Catalina le niega por primera vez a Andrés su cuerpo:

Me trepó el vestido y yo apreté las piernas. Su cuerpo encima me apretaba los broches del liguero.

- ¿Quién lo mató? - pregunté.

-No sé. Las almas puras tienen muchos enemigos - dijo-. Quítate esas mierdas. Está resultando más difícil coger contigo que con una virgen poblana. Quítatelas - dijo mientras sobaba su cuerpo contra mi vestido. Pero yo seguí con las piernas cerradas, bien cerradas por primera vez (74).

Lo cual no quiere decir que no vuelva a hacer el amor con Andrés. Un poco más adelante, al final del capítulo 9 que coincide con el del sexenio de Aguirre-Cárdenas y después de haber aguantado estoicamente un naranjazo de un ferrocarrilero partidario de AlmazánBravo, Catalina, quien ha asistido al desfile del $1^{\circ}$ de mayo junto al candidato "Fito"-Manuel Avila Camacho reacciona así frente al agradecimiento de Andrés por su entereza: "Lo imaginé sentado frente a su escritorio lleno de papeles que nunca leía. Casi vi su boca echando carcajadas de agradecimiento. Algo de él me gustaba todavía" (88).

La rebeldía de Catalina se manifiesta las más veces como resistencia dentro de los límites de su circunstancia vital, como cuando vota por Bravo-Almazán no porque lo "considerara una maravilla" sino porque sabía que iba a perder y el votar por él la exoneraba en cierta forma de toda complicidad con el gobierno de "Fito"-Avila Camacho cuya elección se debió, de acuerdo con la narradora-protagonista al robo de urnas por parte de los militantes del PRM, padre de nuestro PRI. Las calles del D.F. y el aprender a manejar contribuyen también a la emancipación de Catalina, a su educación. Pero el catalizador de su verdadera liberación será su encuentro con Carlos Vives, con el mundo de la música, del arte y de la aspiración por un mundo mejor, por un México más ecuánime, menos corrupto y arbitrario.

Catalina, sin embargo, necesita, a lo largo de su vida con Andrés Ascencio de otras mujeres que propicien su liberación. Ese es el caso de Andrea Palma, por ejemplo, en el capítulo diez y siete, quien le aconseja que, saliendo de la sesión de masaje durante la cual conversan, Catalina se ponga a investigar quién es Andrés Ascencio (149). La protagonista sabe perfectamente quién es su esposo Andrés Ascencio, pero un elemento de lo que los existencialistas llamaran "mala fe" hace que pretenda no saberlo hasta que empiece a temer por su propia vida y por la de Carlos. Hasta escuchar el "chisme" de la masajista Raquel según la cual Andrés asesinó a una de sus amantes en Morelos por rechazarlo, no se le había ocurrido a Catalina que Andrés fuera capaz de asesinar a una mujer con quien se hubiese acostado. En el capítulo diez y ocho trata de cerciorarse de que Andrés sería incapaz de matarla a ella o a Carlos pero en el diez y nueve tiene que enfrentarse al asesinato de Carlos, 
obra de Andrés, celoso, pero aún más receloso de los contactos de Carlos con Medina y con la CTM.

$\mathrm{Al}$ asesinato de Carlos sigue el del novio de Lilia, Javier. En el capítulo 21 que narra la boda en Atlixco de Lilia con Emilito el discurso de la narradora-protagonista parecería traducir su claudicación frente al poder sin grieta alguna de Andrés Ascencio. Sin embargo, aparece el director de cine Quijano, con quien Catalina baila y quien se convertirá en su último amante dentro de la narración y la reaparición de la viuda de Fidel Velázquez quien, de manera totalmente subterránea y sub-textual, se va a convertir en la ayudante de la protagonista proporcionándole el toloache, llamado "té de Carmela" en la novela que será el instrumento de liberación de Catalina. El marido de Carmela había sido asesinado en el ingenio de Atenzingo (o Atenanzinco en la realidad objetiva) propiedad de Heiss-Jenkins por los matones de Andrés y Heiss. La muerte eventual de Andrés vengará también la muerte del marido de Carmela y por extensión la muerte de todos aquellos asesinados o mandados asesinar por Andrés. No porque Catalina le suministre a Andrés grandes cantidades del té de Carmela, sino porque Andrés, dentro de su prepotencia se niega a tomar en serio los consejos de la sirvienta Matilde cuando ésta le advierte que está tomando el té de Carmela con demasiada frecuencia. Como en las tragedias clásicas, Andrés es pues víctima de su propia hubris y es su desmesura, aquí traducida en adicción al toloache la que causa su perdición, su muerte. Hay pues subversión también a nivel del discurso popular según el cual ciertas mujeres utilizan subrepticiamente esta yerba para ir minando paulatinamente la voluntad del esposo y poder así controlarlo mejor. Catalina solamente le ofrece a Andrés el té de Carmela para paliar su dolor de cabeza ya que ella lo ha estado tomando como tranquilizante, pero con mesura. La ironía de la situación salta a la vista y es utilizada por la narradora-protagonista como medio para subvertir el discurso de la tradición popular que es también patriarcal.

En el último capítulo de la novela el discurso de la narradora-protagonista eleva la viudez al estado ideal de la mujer en el México que está por entrar al sexenio alemanista y, probablemente, en 1992 siga siendo el estado que mayor libertad le otorgue a una mujer de las clases privilegiadas, pues está teñido del respeto que se le otorga a la esposa legítima y al "sufrimiento" que el sistema patriarcal le infunde, por definición, al de viudez. Hasta la noción de "viuda alegre" es infinitamente menos perjudicial que la de "divorciada", concepto que es casi sinónimo de "rechazo", sea quien fuere el iniciador del proceso de divorcio, de mujer emancipada fuera de la ley del machismo tradicional. La polisemia implícita en el título y más allá del texto de la canción popular del cual proviene, parece vinculada al mundo vegetal, como si la vida fuera eso, las flores de muerto o cempasúchitl del campo en el cual Catalina y Carlos hicieran el amor antes del asesinato de éste y que ella mandara "arrancar" para que cubrieran su tumba. Las hierbas del té de Carmela que son arrancadas de la tierra y eventualmente "arrancan" la vida de Andrés. Flores y hierbas que aquí simbolizan una forma de subversión del texto. La mujer no es un manojo de hierbas ni un ramo de flores en pasiva espera de que eventualmente se las "arranque" y así se les dé "vida" más allá de la vida vegetal, como adornos, reproductoras de la especie, o como hechiceras-manipuladoras. Tampoco son un manojo de hierbas el pueblo trabajador y los activistas sociales de ambos sexos. El texto de la novela nos empuja a rechazar otro conocido verso de la música popular mexicana, aquél que dice que "la vida no vale nada". 
La lucha en contra de ese desplante machista y nihilista parece esbozarse al final de la novela cuando Catalina nos dice sentirse divertida con su futuro y "casi feliz". Se trata de una tregua importante en el camino, pero todas las lectoras sabemos que no se trata sino de una tregua. 
